\title{
Impact of interlayer on moisture characteristics of reclaimed soil backfilled with Yellow River sediments
}

\author{
Xiaotong Wang ${ }^{1}$, Zhenqi $\mathrm{Hu}^{1,2^{*}}$, Yusheng Liang ${ }^{1}$ \\ (1. Institute of Land Reclamation and Ecological Restoration, China University of Mining and Technology (Beijing), Beijing 100083, China; \\ 2. China College of Environment Science and Spatial Informatics, China University of Mining and Technology, Xuzhou 221116, China)
}

\begin{abstract}
Underground coal mining causes land subsidence, and backfilling with Yellow River sediment is an effective reclamation technology to restore farmland in China. To date, two-layer soil reconstructed (TSR) for subsided land reclamation resulted in poor capacity to retain water. To solve this problem, multi-layered soil reconstructed (MSR), sandwiching soil interlayers between sediment, was developed as a new reclamation strategy with Yellow River sediment. In order to evaluate the impact of soil interlayer on moisture characteristics, laboratory experiments of infiltration and evaporation were conducted. Two control treatments (CK1, CK2) and four experimental treatments (T1-T4) were designed. CK1 was undamaged farmland, CK2 was conventional reconstructed two-layers soil profile (filled sediment with $40 \mathrm{~cm}$ soil cover). T1-T4 were multiple-layers soil profiles sandwiching different structures of soil interlayers between sediment layers. The results indicated that putting interlayers into sediment reduced water leakage and water evaporation, improved the water-holding capacity of conventional two-layer soil profiles. The total thickness of soil interlayers of $30 \mathrm{~cm}$ (T3 and T4) was better than $20 \mathrm{~cm}$ (T1 and T2) and two soil interlayers (T2) were better than one (T1) on water-holding capacity. Furthermore, the best reconstructed soil profile was T3, sandwiched two soil interlayer and the first thickness was $20 \mathrm{~cm}$. This treatment had the greatest improvement on soil water holding capacity with an increase of $49.14 \%$ compared to CK2 at the end of the evaporation and was closest to CK1 $(402.31 \mathrm{~mm})$. This study provided experimental evidence that compares with TSR, MRS improved the moisture characteristics of backfilling with Yellow River sediment.
\end{abstract}

Keywords: land reclamation, Mining subsidence, Yellow River sediment, multi-layered soil reconstructed, moisture characteristics

DOI: $10.25165 /$ j.ijabe.20201301.5418

Citation: Wang X T, Hu Z Q, Liang Y S. Impact of interlayer on moisture characteristics of reclaimed soil backfilled with Yellow River sediments. Int J Agric \& Biol Eng, 2020; 13(1): 153-159.

\section{Introduction}

Coal is the primary energy source in China. However, large-scale coal mining causes serious ecological and environmental problems ${ }^{[1]}$. Extraction of $10000 \mathrm{t}$ of coal from underground creates approximately $0.2-0.33 \mathrm{hm}^{2}$ of subsided lands ${ }^{[2]}$. By 2020, the accumulative total area of destroyed cultivated land was expected to reach $3.83 \times 10^{5} \mathrm{hm}^{2[3]}$. Cultivated land resources are an important basis for the development of agricultural production and have great practical significance for food security and social sustainable development ${ }^{[4]}$. China is a country with a large population, and the conflict between a large population and small cultivated land is very prominent. Therefore, decreases in both quantity and quality of cultivated land have drawn close attention recently due to the threat to food security ${ }^{[5]}$. For restoring farmland in such areas, the common practice is filling subsided areas with available unconsolidated materials ${ }^{[6]}$. To date, the most common filling materials are coal gangue and fly $\operatorname{ash}^{[7]}$, but these materials have some disadvantages such as potential

Received date: 2019-09-22 Accepted date: 2019-12-12

Biographies: Xiaotong Wang, $\mathrm{PhD}$ candidate, research interests: land reclamation and ecological restoration, Email: xiaotong0532@126.com; Yusheng Liang, PhD candidate, research interests: land reclamation and ecological restoration, Email: yusheng20102013@163.com.

*Corresponding author: Zhenqi $\mathrm{Hu}, \mathrm{PhD}$, Professor, research interests: land reclamation and ecological restoration. Room 345 Zonghe Building, D11 Xueyuan Road, Haidian District, Beijing 100083, China. Tel: +8613910637448, Email: huzq1963@163.com. contamination and insufficient quantity ${ }^{[8]}$. Gupta et al. showed that fly-ash affects the physicochemical characteristics of soil and inhibits the normal photosynthesis of plants ${ }^{[9]}$. Hu et al. found that the soil reclaimed by fly ash was, as a whole, polluted according to common soil assessment standards ${ }^{[10]}$. Liu et al. showed that with the action of leaching by rain and water, some hazardous minor elements will be dissolved partially or completely and separated from coal gangue into water or soil environment ${ }^{[11]}$. In contrast, the heavy metal pollution risk in Yellow River sediment is low ${ }^{[12,13]}$.

The Yellow River is one of the highest sediment content rivers in the world ${ }^{[14]}$. To ensure the safety of the Yellow River, the government invests a large amount of money annually to dredge the river, and large areas of land are occupied by the dredged sediment ${ }^{[13]}$. Using Yellow River sediment as filling material for mining subsidence land could help the dredging of the Yellow River and solve the problem of subsidence land reclamation with insufficient filling materials. However, Yellow River sediment is coarse-textured, which limited its water-holding capacity ${ }^{[15]}$. Some experiment has shown that two-layer soil reconstructed (TSR) for subsided land reclamation resulted in low soil productivity as thin soil cover ${ }^{[13,16]}$. Shao et al. ${ }^{[17]}$ proved that the reclaimed soils are characterized by poor soil water holding-capacities by experimental infiltration experiments.

To improve the water-holding capacity of the reconstructed soil profiles, it is important to design a reasonable reconstructed soil profile. There is evidence that multiple layers of soils are more effective in maximizing plant-available water in soil 
reconstruction ${ }^{[18]}$. Romano et al. showed that the order of soil layering significantly affects the processes of soil infiltration and soil water redistribution ${ }^{[19]}$. Zettl et al. ${ }^{[20]}$ highlighted the importance of textural layering in designing reclamation covers in coarse textured soils to enhanced moisture storage. Huang et al. ${ }^{[21]}$ further indicated that the layered soil profile can store more water than similarly textured, vertically homogeneous soils under well-drained conditions. $\mathrm{Hu}$ et al. ${ }^{[22]}$ designed the multi-layered soil reconstructed (MSR) sandwiching soil interlayers between sediment, according to the natural structure of subsided land filled with Yellow River sediment and further evaluated the effect of various soil-sediment layered sequences on maize growth, However, the potential effect of soil interlayer on moisture characteristic of reclaimed soil filled with Yellow River sediment has not been fully explored.

Infiltration and evaporation are important hydrologic processes $^{[23]}$. Therefore, investigations of moisture characteristics on infiltration and evaporation are required to develop effective approaches ${ }^{[24-30]}$. In view of the above facts and research gaps, the objective of this study was to characterize the impact of interlayer on moisture characteristic of reclaimed soil backfilled with Yellow River sediment by infiltration and evaporation experiments were conducted in soil columns.

\section{Materials and methods}

\subsection{Experimental materials}

The study area was located in Liangshan County, Jining City, Shandong Province, China (Figure 1). Experimental soil was collected from a subsidence land along the Yellow River $\left(35^{\circ} 56^{\prime} 39.25^{\prime \prime} \mathrm{N}, 116^{\circ} 0^{\prime} 10.33^{\prime \prime} \mathrm{E}\right)$ to a depth of $60 \mathrm{~cm}$. The texture of soil is silt loam (based on the USDA Soil Taxonomy System) with particle size distributions of $24.48 \%$ in $0.0-0.002 \mathrm{~mm}, 68.66 \%$ in $0.002-0.05 \mathrm{~mm}$, and $6.86 \%$ in $0.05-2 \mathrm{~mm}$ (analyzed with sieve and hydrometer methods). The Yellow River sediment was collected from a diversion gate at the Chengai site $\left(35^{\circ} 52^{\prime} 28.5^{\prime \prime} \mathrm{N}\right.$, $115^{\circ} 53^{\prime} 41.36$ "E). It is loam sandy with particle size distributions of $2.80 \%$ in $0.0-0.002 \mathrm{~mm}, 15.48 \%$ in $0.002-0.05 \mathrm{~mm}$, and $81.72 \%$ in $0.05-2 \mathrm{~mm}$. The experimental soils were air dried and then sieved through a 2-mm mesh for standby application. The initial moisture content of the experimental dry soil and Yellow River sediment were $11.8 \%$ and $2.7 \%$, respectively.

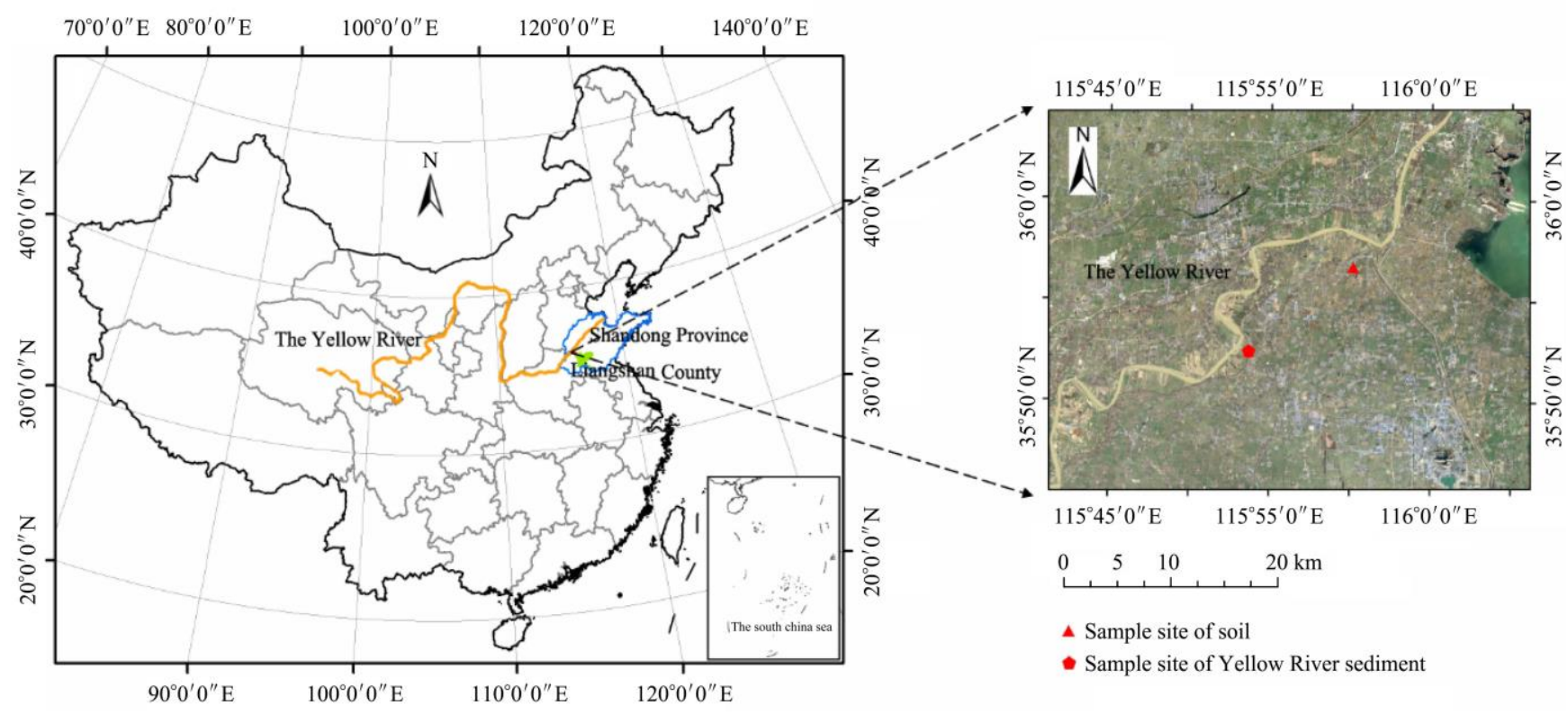

Figure 1 Sample site of soil and Yellow River sediment

\subsection{Experimental methods}

The experimental soil profiles were $120 \mathrm{~cm}$ long, consisted of two control treatments (CK1, CK2) and five treatments with different thicknesses and number of interlayers in Yellow river sediment (T1-T4) (Figure 2). The CK1 was filled with $120 \mathrm{~cm}$ of soil which represents undamaged farmland. CK2 consisted of sediment covered by $40 \mathrm{~cm}$ soil which represents conventional reclaimed two-layers soil profile. Base on the previous greenhouse column study ${ }^{[22]}$, four better treatments (T1-T4) were selected. Treatments T1-T4 consisted of various combinations of soil interlayer and sediment overlain by $40 \mathrm{~cm}$ of subsoil. T1 sandwiched one soil interlayer between sediment, T2, T3, T4 sandwiched two soil interlayers between sediment. T1, T2 put $20 \mathrm{~cm}$ total thickness of soil interlayers into sediment, T3, T4 put $30 \mathrm{~cm}$ total thickness of interlayers into sediment. T3 set the thickness of the first soil interlayer at $20 \mathrm{~cm}$ and $\mathrm{T} 4$ set that at $10 \mathrm{~cm}$.

Experiments were performed in polymethyl methacrylate cylinders with an inner diameter of $10 \mathrm{~cm}$ and a height of $130 \mathrm{~cm}$ (soil columns were all $120 \mathrm{~cm}$ ). The cylinder was packed with soil and Yellow River sediment in $5 \mathrm{~cm}$ increments and compacted to get the designed dry bulk density of $1.35 \mathrm{~g} / \mathrm{cm}^{3}$ and $1.5 \mathrm{~g} / \mathrm{cm}^{3}$, respectively. The surface of each soil layer was corrugated into roughness before the next compacting ${ }^{[28]}$. After the soils were compacted into soil column and stand for $48 \mathrm{~h}$, the infiltration experiment was done.

The height of the Mariotte bottle was adjusted to supply water to the cylinders, and to keep a constant water head of $4 \mathrm{~cm}$. Changes in water content of the Mariotte bottle were recorded to calculate cumulative infiltration. Meanwhile, the lower position of the wetting front was also recorded. The infiltration ended when the wetting front reached the bottom of the soil column. After 2 days, the water content of soil profiles was recorded at positions of $5,15,25,35,45,55,65,75,85,95$ and $105 \mathrm{~cm}$.

The soil column was weighed after infiltration and then placed beneath an infrared lamp ( $275 \mathrm{~W})$ and maintained at a constant $30 \mathrm{~cm}$, followed by the evaporation experiment. The mean room temperature was $(24.5 \pm 0.5)^{\circ} \mathrm{C}$. During evaporation, the soil 
column was weighed every day to calculate cumulative evaporation. Evaporation was completed on the 30th day and moderate amounts soils were collected to measure the water content of the soil profile at $5,15,25,35,45,55,65,75,85,95$ and $105 \mathrm{~cm}$.

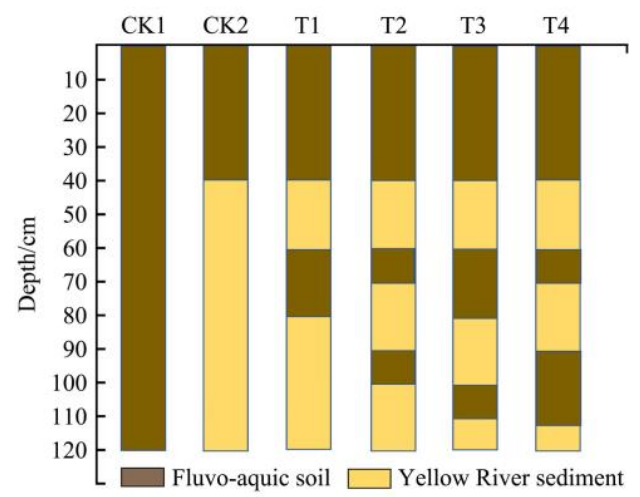

Figure 2 Diagram of different soil profiles

\section{Results and discussion}

\subsection{Impact of interlayer on infiltration}

The cumulative infiltration of different treatments was shown in Figure 3. In the early stage, the cumulative infiltration increased rapidly due to the large water potential gradient. The cumulative infiltration of CK1 exhibited a linear relationship with infiltration during the later stages of the experiment; while the change came earlier in the other treatments. However, at approximately $330 \mathrm{~min}$, the slope of CK2 no longer changed after water entering the sediment layer of the Yellow River, which means that the relationship between the cumulative infiltration and infiltration time was linear and the infiltration rate became constant. At approximately $630 \mathrm{~min}$, when water moved into the soil interlayer, no significant differences $(p<0.05)$ were observed between the Multi-layered soil profiles of T1-T4, and the cumulative infiltration was between CK1 and CK2. At approximately $1350 \mathrm{~min}$, the wetting front moved into the second soil interlayer, and the infiltration rate decreased again. Multi-layered soil profiles (T1-T4) that put soil interlayers into filled sediment enhanced cumulative infiltration of $18.89 \%$, $20.87 \%, 31.81 \%$ and $30.32 \%$ of CK2 respectively when the wetting front arrived at $120 \mathrm{~cm}$ of soil columns, which proved that T1-T4 enhanced water storage of CK2 on infiltration. Soil infiltration characteristics are determined by the soil layer pattern under vertical rainfall infiltration ${ }^{[31]}$. The total thickness of the $30 \mathrm{~cm}$ soil interlayer (T3, T4) had more cumulative infiltration than the total thickness of the $20 \mathrm{~cm}$ soil interlayer (T1, T2). Among them, the cumulative infiltration of T3 was accounted for $83.83 \%$ of CK1 $(510.88 \mathrm{~cm})$ as the closest one.

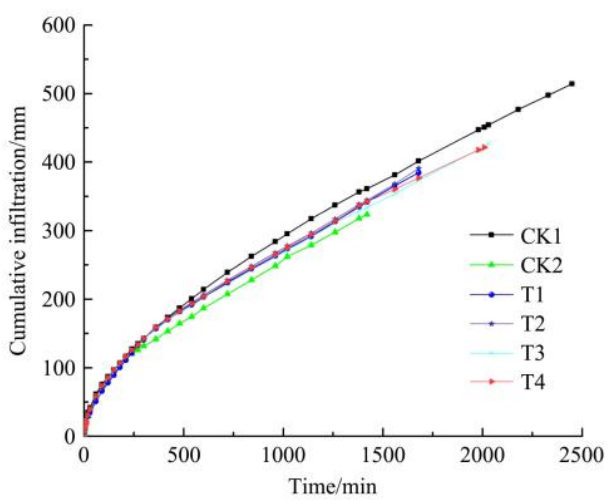

Figure 3 Cumulative infiltration for different treatments
As illustrated in Figure 4, the initial advancement of the wetting front was similar for all treatments. The difference appeared after $300 \mathrm{~min}$ and wetting front crossed the "soil-sand" interface, where migration rate of CK2 continued to increase after entering the Yellow River sediment layer. It reached the bottom of the column in $4500 \mathrm{~min}$, which is only $48.73 \%$ of the time required for CK1. In T1-T4, putting interlayers into filled sediment layer that decreased the downward rate of movement by $18.31 \%, 28.87 \%, 49.29 \%$ and $42.96 \%$, respectively, compared with CK2. In addition, Table 1 showed that the speed of the wetting fronts decreased by an average of $46.0 \%$ when the wetting front entered the soil interlayer for the first time. When the wetting front entered the soil interlayer for the second time reduced less obvious than the first time, the T2, T3, and T4 wetting front speeds decreased by $25.0 \%, 38.2 \%$ and $27.6 \%$, respectively. This indicates that the rate of the wetting front was influenced by the thickness and number of soil interlayer. The resistance effect of MSR with two soil interlayers is better than one, and a first soil interlayer with a thickness of $20 \mathrm{~cm}$ (T3) is better than interlayer with a thickness of $10 \mathrm{~cm}(\mathrm{~T} 2)$.

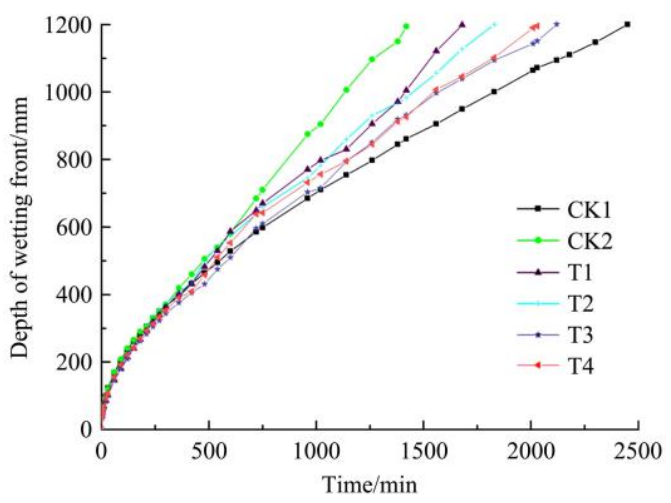

Figure 4 Advance of the wetting front for different treatments

Table 1 Wetting front transport rate in different soil profiles

\begin{tabular}{ccccccc}
\hline & \multicolumn{5}{c}{ Wetting front transport rate/mm· min } \\
Depth/cm & CK1 & CK2 & T1 & T2 & T3 & T4 \\
\cline { 2 - 6 } & 4.76 & 4.76 & 4.45 & 4.17 & 4.35 & 4.45 \\
$10-10$ & 1.49 & 1.51 & 1.35 & 1.47 & 1.32 & 1.33 \\
$20-30$ & 0.85 & 0.91 & 0.92 & 0.88 & 0.81 & 0.81 \\
$30-40$ & 0.62 & 0.60 & 0.61 & 0.62 & 0.65 & 0.67 \\
$40-50$ & 0.55 & 0.70 & 0.72 & 0.74 & 0.73 & 0.72 \\
$50-60$ & 0.48 & 0.74 & 0.9 & 0.84 & 0.85 & 0.82 \\
$60-70$ & 0.39 & 0.76 & 0.5 & 0.46 & 0.43 & 0.45 \\
$70-80$ & 0.38 & 0.78 & 0.37 & 0.54 & 0.38 & 0.52 \\
$80-90$ & 0.36 & 0.76 & 0.45 & 0.56 & 0.51 & 0.58 \\
$90-100$ & 0.36 & 0.78 & 0.64 & 0.42 & 0.61 & 0.42 \\
$100-110$ & 0.33 & 0.76 & 0.77 & 0.59 & 0.37 & 0.35 \\
$110-120$ & 0.33 & 0.76 & 0.77 & 0.58 & 0.45 & 0.37 \\
\hline
\end{tabular}

The Kostiakov model in MATLAB software was used to analyze the relationship between the cumulative infiltration and infiltration time. The model had parameters $k$ and $a$ as follows: $I(t)=k t^{a} \quad(k>0,0<a<1)$

where, $I$ is the cumulative infiltration, $\mathrm{mm} ; t$ is time, min; $k$ and $a$ are empirical estimates.

The results are shown in Table 2, for all treatments, $R^{2}$ values were larger than 0.993 and the RRMSE values were smaller than 0.0613. These results indicated that the Kostiakov model was well fitted. 
Table 2 Cumulative infiltration and wetting front of remixed soil by each treatment

\begin{tabular}{cccc}
\hline \multirow{2}{*}{ Soil profile } & \multicolumn{3}{c}{ Cumulative infiltration fitting } \\
\cline { 2 - 4 } & $I(t)=k t^{a}$ & $R^{2}$ & RRMSE \\
\hline CK1 & $I(t)=4.110 t^{0.6180}$ & 0.9996 & 0.0228 \\
CK2 & $I(t)=4.792 t^{0.5771}$ & 0.9972 & 0.0613 \\
T1 & $I(t)=4.321 t^{0.6020}$ & 0.9979 & 0.0596 \\
T2 & $I(t)=4.698 t^{0.5919}$ & 0.9986 & 0.0553 \\
T3 & $I(t)=4.505 t^{0.5951}$ & 0.9983 & 0.0412 \\
T4 & $I(t)=4.791 t^{0.5876}$ & 0.9992 & 0.0231 \\
\hline
\end{tabular}

\subsection{Impact of interlayer on evaporation}

The evaporation process can be regarded as the process of liquid water changing into vapor and flowing from the soil pores into the atmosphere ${ }^{[32]}$. Evaporation is one of the most important phases in the water cycle ${ }^{[29]}$. Steady evaporation from soils is not a widespread occurrence. Even where a high water table exists, neither its depth nor external conditions can remain constant for very long ${ }^{[33]}$. In general, the evaporation process can be divided into three stages ${ }^{[29]}$. The maximum daily evaporation intensity was observed in the homogeneous soil profile CK1 (Figure 5). In the first stage (day 0 to day 10), all treatments had the highest evaporation intensity, and the trend was basically identical due to the higher water content and greater hydraulic conductivity of soil at the beginning of evaporation. The surface soil water content gradually decreased until it overcame gravity, and the subsoil water constantly moved toward the topsoil. In this stage, the intensity of soil evaporation is mainly influenced by atmospheric evaporation power, which leads to topsoil water recharge from deep soil and a considerable loss of soil water via evaporation. At the second stage (day 10 to day 23), the hydraulic potential gradient of the subsoil gradually increased, the surface soil water content gradually decreased, and the unsaturated hydraulic conductivity decreased faster as soil water suction increased. During this stage, the intensity of soil evaporation is mainly influenced by the soil water conductivity, and the evaporation rates gradually decreased. In addition, the duration of the second stage was longer than that of the first stage. At the third stage (day 23 to day 30), the intensity of soil evaporation was low and tended toward stagnation; water was no longer vaporized directly into the atmosphere from the soil surface but diffused from the lower layer of wet soil. The Multi-layered soil profiles (T1, T2, T3, T4) produced consistent results for all three stages of the evaporation process, and the inhibitory effect of the interlayer on evaporation was greatest in the second stage.

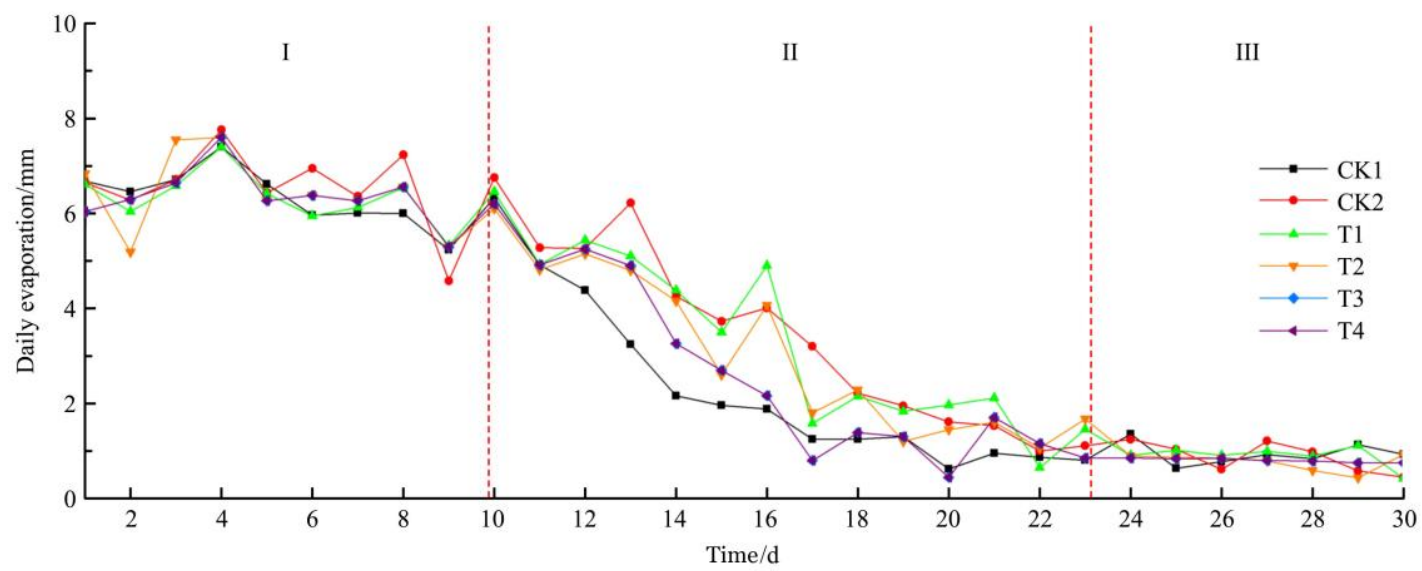

Figure 5 Evaporation intensity for different treatments

The cumulative evaporation of different treatments was sorted as $\mathrm{CK} 2>\mathrm{T} 1>\mathrm{T} 2>\mathrm{T} 4>\mathrm{T} 3>\mathrm{CK} 1$ (Figure 6). The cumulative evaporation of CK2 is the maximum, 1.18-fold the minimum evaporation of CK1. At the end of the first stage of evaporation (day 10), the cumulative evaporation amounts of CK2, T1, T2, T3 have no significant difference $(p>0.05)$. The test treatments of soil profile overlying soil thickness were all $40 \mathrm{~cm}$. Soil water overcame gravity and moved through the capillary as a constant supply of topsoil evaporated under the action of the matrix suction. Putting the soil interlayer into sediment layers, to some extent, inhibited the water evaporation. The water in the sediment layers will gather in the soil interlayers in evaporation controlled by capillary force. Different structures of interlayer have different effects on reduced the cumulative evaporation. In T1-T4, that reduced the cumulative evaporation by $3.11 \%, 6.34 \%, 11.67 \%$ and $10.93 \%$, respectively, compared with CK2. This indicated that soil moisture loss was reduced by putting soil interlayers in the sediment. The matrix suction through multiple soil layers in a soil profile was discontinuous, and the capillary rise in water was reduced. The reduction in evaporation improves the storage capacity and water use efficiency of the soil ${ }^{[34]}$. Therefore, the MSR putting the total thickness soil interlayers of $30 \mathrm{~cm}$ was better than $20 \mathrm{~cm}$ into sediment and two soil layers were better than one on water-holding capacity.

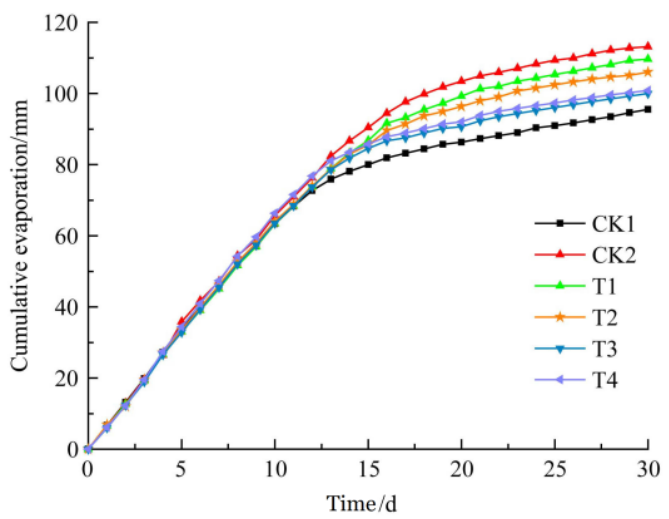

Figure 6 Cumulative evaporation for different treatments

The fitting results (Table 3) showed that the exponential $R^{2}$ were all greater than 0.941 , and the RRMSE was all less than 0.0786. A polynomial regression of $R^{2}$ was greater than 0.992 , and the RRMSE was less than 0.0274. For all treatments, the $R^{2}$ of the polynomial regression were greater than those of the exponential relationships. Therefore, the polynomial regression 
equation $Y=a t^{2}+b t+c$ was used for a well fit, where $Y$ represents the cumulative evaporation (mm); $t$ is time (d); and $a, b$ and $c$ are all equation coefficients.

Table 3 Fitting results of cumulative evaporation of various soil columns with time

\begin{tabular}{cllcc}
\hline \multirow{2}{*}{ Treatments } & \multicolumn{1}{c}{ Fitting type } & \multicolumn{1}{c}{ Fitting equation } & $R^{2}$ & RRMSE \\
\hline \multirow{2}{*}{ CK1 } & exponent relation & $Y=9.587 t^{0.735}$ & 0.941 & 0.0641 \\
& polynomial regression & $Y=-0.156 t^{2}+7.554 t+0.509$ & 0.992 & 0.0144 \\
\hline \multirow{2}{*}{ CK2 } & exponent relation & $Y=8.480 t^{0.837}$ & 0.971 & 0.0463 \\
& polynomial regression & $Y=-0.156 t^{2}+8.651 t-4.178$ & 0.997 & 0.0235 \\
\hline \multirow{2}{*}{ T1 } & exponent relation & $Y=9.289 t^{0.762}$ & 0.951 & 0.0589 \\
& polynomial regression & $Y=-0.157 t^{2}+7.861 t-0.792$ & 0.993 & 0.0176 \\
\hline \multirow{2}{*}{ T2 } & exponent relation & $Y=8.322 t^{0.828}$ & 0.972 & 0.0737 \\
& polynomial regression & $Y=-0.149 t^{2}+8.27 t-3.852$ & 0.998 & 0.0157 \\
\hline \multirow{2}{*}{ T3 } & exponent relation & $Y=8.601 t^{0.789}$ & 0.951 & 0.0752 \\
& polynomial regression & $Y=-0.156 t^{2}+7.892 t-1.598$ & 0.994 & 0.0245 \\
\hline \multirow{2}{*}{ T4 } & exponent relation & $Y=8.915 t^{0.784}$ & 0.943 & 0.0786 \\
& polynomial regression & $Y=-0.1628 t^{2}+8.105 t-1.88$ & 0.992 & 0.0274 \\
\hline \multirow{2}{*}{}
\end{tabular}

\subsection{Impact of interlayer on Water Retention}

After the soil infiltration process was completed, a water potential gradient was still observed in the soil profile. Soil water continues to move and be redistributed under the action of the water potential gradient until there is no longer a gradient in the soil profile ${ }^{[29]}$ Before evaporation, water was evenly distributed in the profile, and the depth of the CK1 water content was between $30.7 \mathrm{~cm}^{3} / \mathrm{cm}^{3}$ and $33.8 \mathrm{~cm}^{3} / \mathrm{cm}^{3}$, which showed that homogeneous soil has a strong suction force (Figure 7a). On day 30, the profile water content of the CK1 was reduced to between $15.2 \mathrm{~cm}^{3} / \mathrm{cm}^{3}$ and $22.8 \mathrm{~cm}^{3} / \mathrm{cm}^{3}$, and the topsoil water content was even less. The evaporation intensity of CK1 was almost the same as in the early stage of evaporation. Additionally, the water loss from the topsoil was more during the process of evaporation, in which the water loss from the homogeneous soil water loss was continuous and that from the layered soil was discontinuous. The soil in different layers has different textures, which leads to discontinuities in the capillary pores. Figures $7 \mathrm{~b}-7 \mathrm{f}$ show the water content change curves of the layered soil columns. Because of the soil interlayer change of the vertical distribution of water in soil profiles, the soil water in $\mathrm{T} 1, \mathrm{~T} 2, \mathrm{~T} 3$ and $\mathrm{T} 4$ were mainly below $40 \mathrm{~cm}$ layers. The soil water content in the sediment layer of the Yellow River was approximately $7 \mathrm{~cm}^{3} / \mathrm{cm}^{3}$, and in the soil interlayer it increased to more than $30 \mathrm{~cm}^{3} / \mathrm{cm}^{3}$, thus showing the accumulation of water. Due to the low soil suction of the sediment layer of the Yellow River, water of the soil interlayer had difficulty reaching the upper layer; this sediment led to an obstruction of the water supply, which had an inhibitory effect on water evaporation.
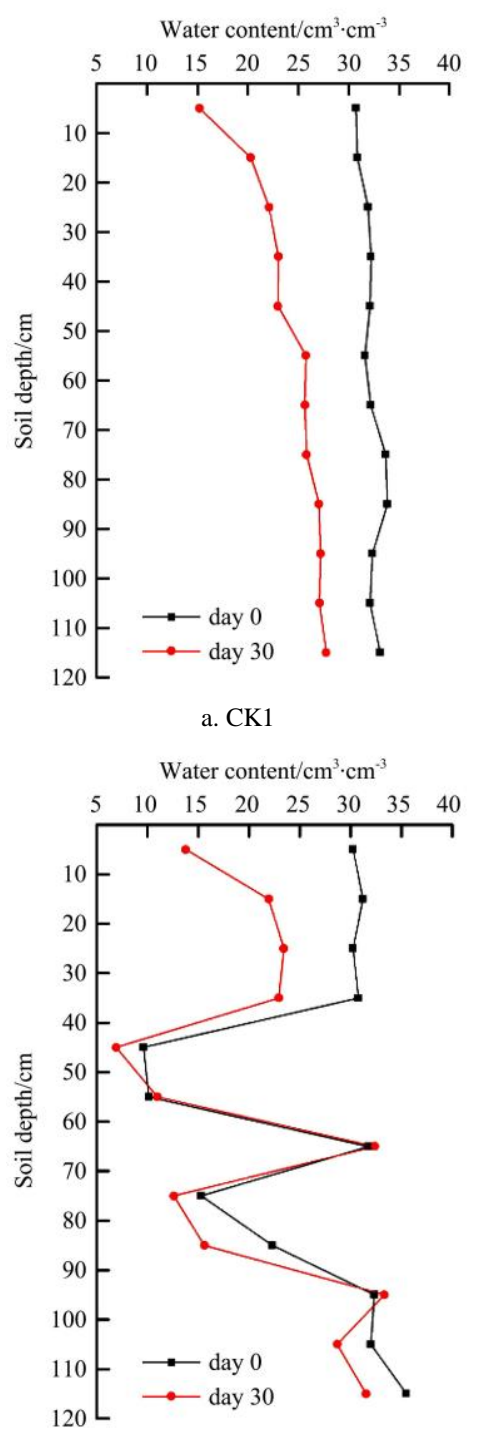

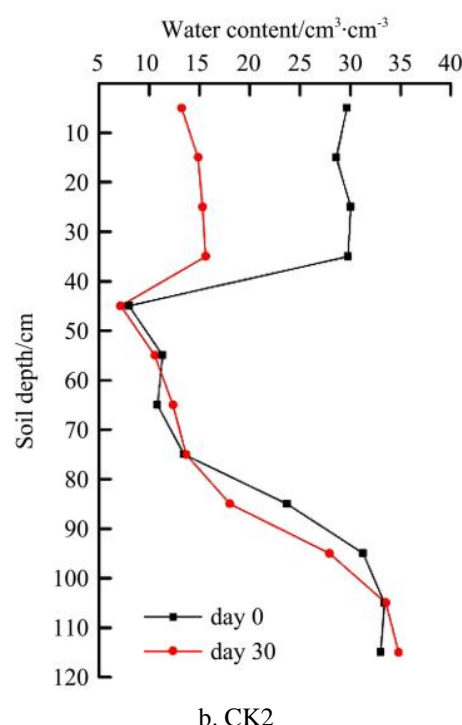

b. CK2

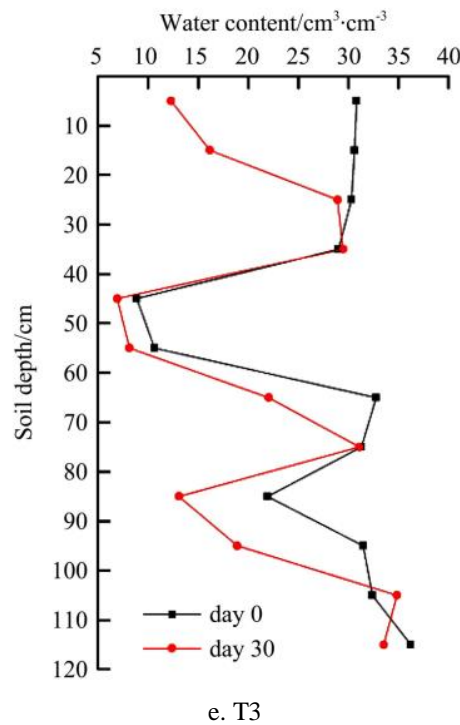

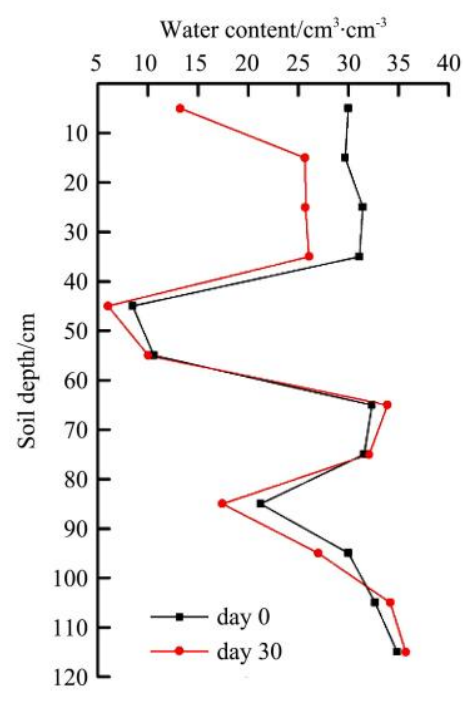

c. T1

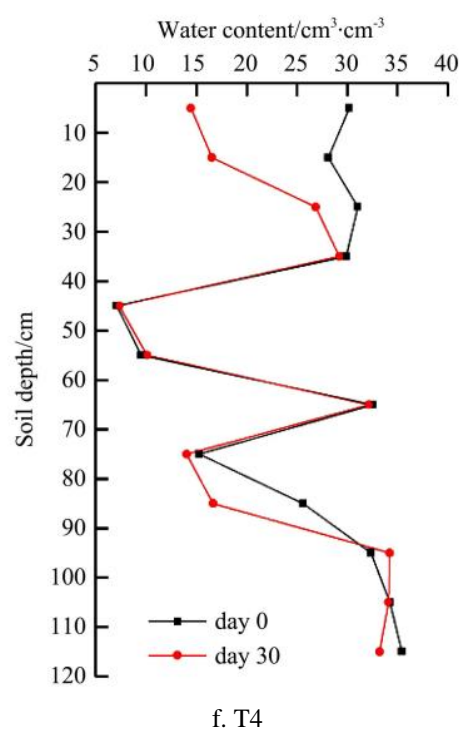

Figure 7 Soil water distribution for different treatments 
According to the stages of evaporation, day 0, day 10, day 23 and day 30 were selected to compare and analyze the water-holding capacity of different columns (Figure 8). In three stages, the water-holding capacities of the different treatments were all ranked as $\mathrm{CK} 1>\mathrm{T} 3>\mathrm{T} 4>\mathrm{T} 2>\mathrm{T} 1>\mathrm{CK} 2$. The two-layers soil profiles $(\mathrm{CK} 2)$ had the lowest water-holding capacity. Multi-layered soil profiles (T1-T4) all improved the water-holding capacities than two-layers soil profiles. At the first stage of evaporation, there were no significant differences $(p>0.05)$ between T1 and T2. However, with time going, the gap between $\mathrm{T} 1$ and $\mathrm{T} 2$ was gradually increased. At the end of evaporation, water-holding capacities for $\mathrm{T} 1, \mathrm{~T} 2, \mathrm{~T} 3$ and $\mathrm{T} 4$ were improved by $36.63 \%, 41.85 \%, 64.16 \%$ and $56.82 \%$, respectively, compared with CK2. That is to say, the result indicated that total thickness soil interlayers of $30 \mathrm{~cm}$ were better than $20 \mathrm{~cm}$ and two soil layers were better than one on water-holding capacity. In addition, at the end of the evaporation $\mathrm{T} 3$ presented the highest water-holding capacity, had an increase of $64.16 \%$ compared to CK2 and was accounted for $80.67 \%$ of CK1 $(402.31 \mathrm{~mm})$ as the closest one. This is similar to the conclusion obtained by Huang et al. ${ }^{[35]}$. There are two basic controls on water movement in these types of systems: When coarser soil overlies finer soil transient, downward water flow may be restricted by the lower hydraulic conductivity of the underlying finer layer. When finer soil overlies coarser soil, a capillary barrier may be existed in which there is insufficient matric suction developed at the top of the coarser layer to draw water from the finer-textured layer ${ }^{[33]}$. The final result of these two effects is that texturally variable profiles often store more water than expected on the basis of estimates of available water holding capacity made from the average soil texture of the soil profile ${ }^{[36]}$.

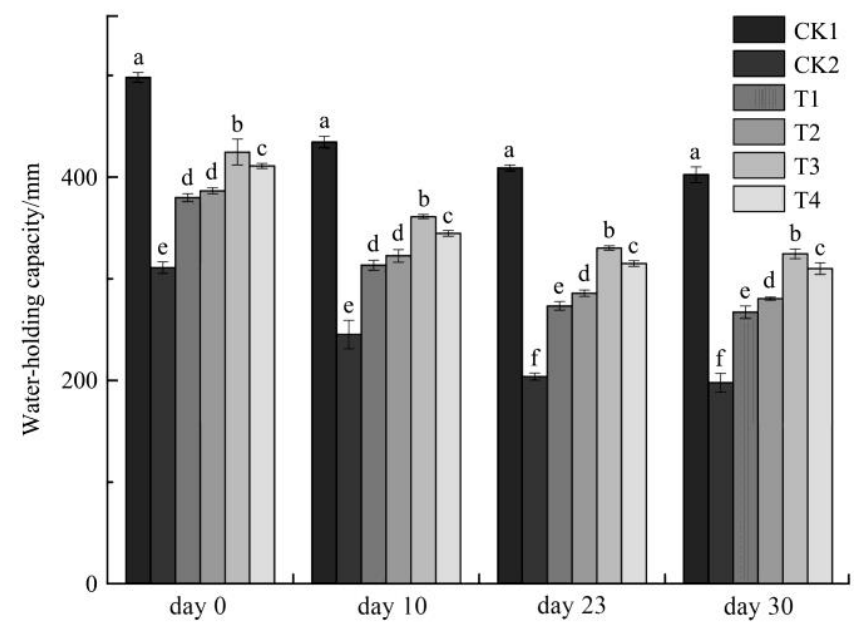

Figure 8 Histogram of water-holding capacity for different treatments

\section{Conclusions}

MSR is a new strategy to reclaim subsidence land with Yellow river sediment. The soil interlayers were shown to improve moisture characteristics of the reclaimed soils. The multiple-layers soil profiles (T1, T2, T3, T4) that putting soil interlayers into sediment reduced water leakage, moisture evaporation and enhanced the water holding capacity of soil moisture than two-layers soil profile (CK2). In addition, different structures of multiple-layers soil profiles were shown to affect moisture characteristics of the reclaimed soils. The total thickness soil interlayers of $30 \mathrm{~cm}$ (T3 and T4) was better than $20 \mathrm{~cm}$ (T1 and T2) and two soil interlayers (T2) were better than one (T1) on water-holding capacity. Furthermore, placing two subsoil interlayers between sediment layers and the first thickness is $20 \mathrm{~cm}$ (T3) resulted in the greatest reduction of percolation. The wetting front reached the bottom of the soil column consumed $2120 \mathrm{~min}$, increased $49.27 \%$ compared to CK2. Its greatest improved soil water holding capacity had an increase of $49.14 \%$ compared to CK2 at the end of the evaporation, accounted for $80.67 \%$ of CK1 $(402.31 \mathrm{~mm})$ as the closest one.

This study provided evidence that the soil interlayers improved the quality of the reclaimed soil on soil moisture characteristics. The MSR as a new strategy is of great improvement than TSR, helps to improve the ecological environment of subsided land and restore farmland with high quality.

\section{Acknowledgements}

This work was financially supported by the National Natural Science Foundation of China (No. 41771542). The authors would like to express appreciation to members of the research group at the China University of Mining and Technology for providing great help in terms of experiments.

\section{[References]}

[1] Hu Z Q, Yang G H, Xiao W, Li J, Yang Y Q, Yu Y. Farmland damage and its impact on the overlapped areas of cropland and coal resources in the eastern plains of China. Resources Conservation \& Recycling, 2014; 86(3): 1-8. (in Chinese)

[2] Xiao W, Hu Z Q, Chugh Y P, Zhao Y L. Dynamic subsidence simulation and topsoil removal strategy in high groundwater table and underground coal mining area: A case study in Shandong Province. International Journal of Mining, Reclamation and Environment, 2016; 28(4): 250-263.

[3] $\mathrm{Hu} \mathrm{Z} \mathrm{Q}$, Xiao W. Optimization of concurrent mining and reclamation plans for single coal seam: a case study in northern Anhui, China. Environmental Earth Sciences, 2013; 68(5): 1247-1254.

[4] Tanrivermis, H. Agricultural land use change and sustainable use of land resources in the Mediterranean region of Turkey. J. Arid Environ, 2003; 54: 553-564.

[5] Zhang X S, Zhang M M, He Z, Wang Q X, Li D S. The spatial-temporal characteristics of cultivated land and its influential factors in the low Hilly Region: A case study of Lishan Town, Hubei Province, China. Sustainability, 2019; 11: 3810-3828. (in Chinese)

[6] Hu Z Q, Wang P J, Shao F. Technique for filling reclamation of mining subsidence land with Yellow River sediment. Transactions of the CSAE, 2015; 31(03): 288-295. (in Chinese)

[7] $\mathrm{Hu} \mathrm{Z}$ Q. Land Reclamation and Ecological Reconstruction; China University of Mining and Technology Press: Xuzhou, China, 2008.

[8] Tang Q, Li L, Zhang S, Zheng L, Mao C H. Characterization of heavy metals in coal gangue-reclaimed soils from a coal mining area. Journal of Geochemical Exploration, 2018; 186: 1-11.

[9] Gupta D K, Rai U N, Tripathi R D, Inouhe M. Impacts of fly-ash on soil and plant responses. Journal of Plant Research, 2002; 115(6): 401-409.

[10] Hu Z Q, Qi J Z, Si J T. Contamination and assessment of heavy metals in fly ash reclaimed soil. Transactions of the CSAE, 2003; 19(2): 214-218. (in Chinese)

[11] Liu G Y, Yang P Y, Peng Z C, Wu E J, Wang G L. Study on leaching of potentially hazardous trace elements from coal-waste rocks. Geological Journal of China Universities, 2001; 12(4): 423-427.

[12] Zhang J, Huang W W, Martin J M. Trace metals distribution in Huanghe (Yellow River) estuarine sediments. Estuarine Coastal and Shelf Science, 1988, 26(5): 499-516.

[13] Wang P J, Hu Z Q, Shao F, Jiang Z D, Qiao Z Y, Liu D W, et al. Feasibility analysis of Yellow River sediment used as the filling reclamation material of mining subsidence land. J. China Coal Soc, 2014; 39(6): 1133-1139.

[14] Zhang Z K, Wang S M, Yang X D, Jiang F C, Shen J, Li X S. Evidence of a geological event and environmental change in the catchment area of the Yellow River at 0.15 Ma. Quat. Int, 2004; 117(1): 35-40. 
[15] Wang X T, Hu Z Q, Liang Y S, Chen Y. Optimal bulk density infilling reclamation of mining subsidence land with Yellow River sediment based on water characteristics. Transactions of the CSAE, 2018; 34(16): 258-264. (in Chinese)

[16] Hu Z Q, Duo L H, Shao F. Optimal thickness of soil cover for reclaiming subsided land with yellow river sediments. Sustainability, 2018; 10(11): 3853-3864.

[17] Shao F, Wang P J, Hu Z Q, Zeng J Y, Chen Y K, Li E L. Vertical Infiltration characteristics of reclamation farmland soil filled with the Yellow River sediment. Journal of soil and water conservation, 2013; 27(5): 54-67.

[18] Moskal T. Moisture characteristics of coarse textured soils and peat: mineral mixtures. MSc Thesis, Department of Renewable Resources, University of Alberta, 1999

[19] Romano N, Brunone B, Santini A. Numerical analysis of one-dimensional unsaturated flow in layered soils. Water Resour, 1998; 21(4): 315-324.

[20] Zettl J D, Barbour S L, Huang M B, Si B C. Influence of textural layering on field capacity of coarse soils. Canadian Journal of Soil Science, 2015; 91(2): 133-147.

[21] Huang M, Barbour S L, Elshorbagy A, Zettl J D, Si B C. System dynamics modeling of infiltration in layered coarse textured soil. Canadian Journal of Soil Science, 2011; 91(2): 185-197.

[22] Hu Z Q, Shao F, Kevin M S. Reclaiming subsided land with Yellow River sediments: evaluation of soil sediment columns. Geoderma, 2017; 307: 210-219.

[23] Gao L, Shao M G. Temporal stability of soil water storage in diverse soil layers. Catena, 2012; 95: 24-32.

[24] Xing X G, Li Y B, Ma X Y. Effects on infiltration and evaporation when adding rapeseed-oil residue or wheat straw to a loam soil. Water, 2017; 9: $700-712$

[25] Sorrenti G, Ventura M, Toselli M. Effect of biochar on nutrient retention and nectarine tree performance: A three-year field trial. Journal of Plant
Nutrition and Soil Science, 2016; 179(3): 336-346.

[26] Li B, Gao J, Wang X, Ma L, Cui Q, Vest M. Effects of biological soil crusts on water infiltration and evaporation Yanchi Ningxia Maowusu desert China. International Journal of Sediment Research, 2016; 31(4): 311-323.

[27] Ma Y, Feng S Y, Su D Y, Gao G Y, Huo Z L. Modeling water infiltration in a large layered soil column with a modified Green-Ampt model and HYDRUS-1D. Computers and Electronics in Agriculture, 2010; 71(S): 40-47.

[28] Wang C Y, Mao X M, Hatano R. Modeling ponded Infiltration in fine textured soils with coarse interlayer. Soil Science Society of America Journal, 2014; 78(3): 745-753.

[29] Shao M A, Wang Q J, Huang M B. Soil Physics, Chinese: Higher education press, 2006.

[30] Hillel D, Baker R S. A descriptive theory of fingering during infiltration into layered soils. Soil Sci, 1988; 146(1): 51-55.

[31] Gan Y D, Jia Y W, Qiu Y Q,Wang K. Stratified Soil Infiltration characteristics during rainfall. Journal of Soil and Water Conservation, 2012; 26(5): 217-219, 223

[32] Hillel D. Environmental soil physics: fundamentals, applications, and environmental considerations, Academic Press, 1998. (in Chinese)

[33] Khire M V, Benson C H, Bosscher P J. Capillary barriers: design variables and water balance. Journal of Geotechnical and Geoenvironmental Engineering, 2000; 126(8): 695-708.

[34] Xing X, Ma X, Shi W. Lysimeter observation and model simulation of groundwater evaporation under bare and film-covered ground conditions. Fresenius Environ. Bull, 2016; 25: 1494-1501.

[35] Huang M B, Julie D, Zettl S, Barbour L, Amin E. Bing C S. The impact of soil moisture availability on forest growth indices for variably layered coarse-textured soils. Ecohydrology, 2013; 6(2): 214-227.

[36] Alfnes E, Kinzelbach W, Aagaard P. Investigation of hydrogeologic processes in a dipping layer structure: 1 . The flow barrier effect. Journal of Contaminant Hydrology, 2004; 69(4): 157-172. 